\title{
O que pensam as crianças ouvintes a respeito da inclusão de crianças surdas no ensino regular: um estudo comparativo com crianças brasileiras de uma escola pública e uma escola privada
}

\author{
Beatriz Vargas Dorneles* \\ Virginia Bedin** \\ Isabel Cristina Peregrina Vasconcelos ${ }^{\star * *}$ \\ Rosane da Conceição Vargas ${ }^{\star \star \star *}$
}

\section{Resumo}

O presente estudo investiga como crianças ouvintes descrevem a inserção de uma criança surda em uma sala de aula. Analisa-se a influência da classe social em relação à aceitação da criança surda pelas crianças ouvintes. Participaram do estudo 144 crianças, de $3^{\mathrm{a}}$ a $5^{\mathrm{a}}$ séries, assim distribuídas: 76 de uma escola privada e 68 de uma escola pública, ambas pertencentes ao município de Porto Alegre, RS. A escola pública atende fundamentalmente às classes sociais de nível socioeconômico baixo, e a escola privada atende alunos de classe social predominantemente média e alta. Todos receberam a mesma tarefa: completar uma história que descrevia a reação de crianças ouvintes à inserção de uma nova colega surda na turma. O estudo demonstra que os alunos têm a intenção de realizar alguma forma de comunicação com a criança surda e de promover momentos de integração dentro e fora do ambiente de sala de aula, embora demonstrem um discurso de certa forma protetor em relação a esse sujeito que consideram não apto, mas ainda capaz de se comunicar. Compreender como crianças ouvintes poderiam relacionar-se e incluir uma criança surda em sala de aula levanta possibilidades de novas formas de pensar a preparação de tais crianças para eventuais processos de inclusão. Reconhecer as ideias, sentimentos e formas de comunicação das crianças auxilia as instituições educacionais a investir em políticas de inclusão.

Palavras-chave: Inclusão escolar. Representação social. Educação especial.

\footnotetext{
* Professora Doutora da Universidade Federal do Rio Grande do Sul, Porto Alegre, Rio Grande do Sul, Brasil.

** Professora da Rede Municipal de Educação de Porto Alegre e doutoranda da Universidade Federal do Rio Grande do Sul, Porto Alegre, Rio Grande do Sul, Brasil.

*** Professora do Centro Universitário Metodista IPA, Porto Alegre, Rio Grande do Sul, Brasil. **** Professora da Pontifícia Universidade Católica de Porto Alegre e doutoranda da Universidade Federal do Rio Grande do Sul, Porto Alegre, Rio Grande do Sul, Brasil.
} 
What hearing children think regarding the inclusion of deaf children in the regular classroom: a comparative study with Brazilian children in a public and a private school

\begin{abstract}
The present study investigates how hearing children relate to the presence of a deaf child in a classroom group. An analysis is made of the influence of social class in relation to the acceptance of the deaf child by the hearing children. The 144 children from the $3 r d$ to 5 th series that participated in the study were distributed thus: 76 from a private school and 68 from a public school, both from Porto Alegre, RS. The public school largely attended lower level socioeconomic classes, while the private school attended pupils from predominantly middle to upper social classes. All received the same task: Complete a story that describes the reaction of hearing students to the insertion of a new deaf colleague in the classroom group. The study demonstrates that pupils wish to attempt to communicate with the deaf child and would socialize with the child outside the classroom. They demonstrate a somewhat protective discourse in relation to the subject who they consider disabled but not incapable of communicating. Understanding how hearing children relate to, and include a deaf child within the classroom, raises the possibility of new forms of thinking regarding the preparation of hearing children to possible inclusion processes. Recognizing their ideas, feelings and forms of communication aids educational institutions to invest in inclusion policies.
\end{abstract}

Keywords: School inclusion. Social representation. Special educatio.

\title{
1 Introdução
}

A educação inclusiva ganhou força nos anos 1990 a partir da Conferência Mundial de Educação para Todos, realizada na Tailândia, em 1990, e da Conferência Mundial de Educação Especial, realizada na Espanha, em 1994. Desta última, originou-se a Declaração de Salamanca (UNESCO, 1994, p. 2), na qual dois artigos se destacam: "as crianças e jovens com necessidades educativas especiais devem ter acesso às escolas regulares"; e tais escolas "constituem os meios mais capazes para combater as atitudes discriminatórias, criando comunidades abertas e solidárias, construindo uma sociedade inclusiva e atingindo a educação para todos". Assim o ensino regular passa por um redimensionamento do seu papel de atender a todos. Tal redimensionamento inscreve-se em um movimento mais amplo, constituído pelas reformas que a sociedade vem sofrendo nas visões de ciência e de mundo. Já não se vivem as certezas dos séculos XIX e XX. Posto isto, pode-se dizer que o movimento de inclusão causa inquietude, desconforto com a perspectiva do confronto com o novo e, principalmente, a constatação da diversidade que impulsiona a compreensão da alteridade. Articular as temáticas educação e inclusão é, assim, uma 
O que pensam as crianças ouvintes a respeito da inclusão de crianças surdas no ensino regular: um estudo comparativo com crianças brasileiras de uma escola pública e uma escola privada

tarefa indispensável nos dias atuais por aliar formas de garantir acesso e permanência de qualidade de ensino e aprendizagem para todos.

O processo de inclusão, pela sua complexidade, passa pela preparação de alunos e professores que vão trabalhar com a criança incluída. Beyer (2005, p. 55) aponta a importância de reconhecer e de conviver com as diferenças em contextos escolares inclusivos, pois estes compõem "um rico campo de aprendizagens, onde as crianças crescem desenvolvendo habilidades tais como as da tolerância e aceitação do outro, importantes para sua vida social e profissional". No entanto, existe pouca literatura a respeito da preparação das crianças do ensino regular em relação a crianças com necessidades educativas especiais, considerando os sentimentos, as representações, as dificuldades e os comentários de crianças que participam de processos inclusivos (LACERDA, 2007). Da mesma forma, são poucos os estudos sobre a representação que as crianças surdas têm em relação à sua inclusão.

Lacerda (2007) entrevistou duas alunas ouvintes e um aluno surdo e sua intérprete. Tais estudantes pertenciam à $5^{\mathrm{a}}$ série do ensino regular. As alunas ouvintes relataram prazer em ter um colega "diferente", entretanto alegaram dominar de forma rudimentar a língua de sinais e conhecer muito pouco a temática da surdez. Já o aluno surdo, por conviver apenas com alunos ouvintes, considerava adequada a sua relação com os demais colegas. A autora destaca que existe respeito pelas diferenças, mas as relações entre alunos ouvintes e surdos são superficiais, muito diferente das relações estabelecidas entre pares (ouvintes $X$ ouvintes e surdos $X$ surdos). Na pesquisa, o aluno surdo sabia pouco sobre seus colegas, não sustentava conversas mais profundas, mantinha trocas comunicativas limitadas, e tinha um relacionamento restrito com seus professores. A intérprete mostrou ser a grande interlocutora entre o aluno surdo e demais componentes da turma: alunos ouvintes e professores. Também já existem estudos que descrevem as expectativas dos professores quanto às crianças incluídas, suas vivências e sentimentos (MACIEL, 2007).

As representações sociais que as crianças ouvintes têm em relação à criança surda compõem um campo fértil de pesquisas a ser explorado e podem trazer contribuições para a compreensão do processo inclusivo no qual as crianças estão envolvidas. Sabe-se que as representações sociais desenvolvem-se no cotidiano, a partir da ressignificação de vivências pessoais, e manifestam-se através dos rituais, valores, conceitos e linguagem do grupo social do qual pertencem (BITTENCOURT; MONTAGNOLI, 2007). A forma de o sujeito compreender o mundo e de representá-lo não pode ser vista de maneira isolada, desconsiderando o contexto social do qual cada criança participa (MOSCOVICI, 1995). Sendo assim, refletir sobre tais representações possibilita um maior entendimento dos significados e da relevância do contexto social na vida da criança.

Compreender como os ouvintes percebem um colega surdo em aula passa pelo entendimento do que é linguagem, língua e comunicação, pois a 
diferença entre surdos e ouvintes está no tipo de comunicação usado entre esses dois grupos.

A linguagem é a forma mais significativa de comunicação e de inserção social, pois a partir dela são compartilhadas as representações sociais. A complexa vida em sociedade permite que diversificados meios de mediação sejam usados para conhecer, comunicar experiências e ideias e transformar o mundo. Assim, o homem cria instrumentos de mediação, materiais e simbóli$\cos$, que regulam as ações sobre os objetos e ampliam a possibilidade de intervenção na natureza. A linguagem é um sistema simbólico que se caracteriza fundamentalmente por organizar os signos em estruturas complexas e por desempenhar um papel determinante na formação das características psicológicas humanas. Por meio dela os seres humanos são capazes de categorizar o mundo; abstrair e generalizar; pensar a respeito dos objetos sem que eles estejam presentes; transmitir ideias situadas no tempo e espaço; comunicar-se, garantindo a preservação de informações e experiências adquiridas pela humanidade ao longo de sua história (BEDIN, 2007). Esse conceito de linguagem é amplo e está fortemente vinculado à relação pensamento e linguagem.

Os sujeitos surdos encontram dificuldades de interação com o grupo social das pessoas ouvintes em que estão inseridos, uma vez que a habilidade linguística de comunicação é diferente em pessoas que se comunicam através da língua oral. Antia e Kreimeyer (2003), baseados na pesquisa de Antia e Dittilo (1998), compararam a interação social entre 38 crianças surdas e 44 ouvintes. Durante um jogo social, as crianças foram divididas em pequenos grupos e, em cada grupo de crianças ouvintes, havia pelo menos duas surdas. O resultado dessa pesquisa indica que as crianças surdas interagem menos com as crianças ouvintes e que isso, possivelmente, ocorra devido a habilidades linguísticas distintas.

Entretanto, é possível constatar que as crianças surdas, quando têm a oportunidade de interagirem com seus pares de mesma modalidade comunicativa, fazem-no sem dificuldades. Minnett, Clark e Wilson (1994) salientam que não há diferença na quantidade de interações entre crianças surdas e ouvintes, embora essa interação seja mais efetiva quando ocorre entre seus pares de mesma modalidade linguística.

Por esse motivo, quando uma criança surda é incluída no ensino regular, há necessidade de preparar as demais crianças para esse convívio. As dificuldades encontradas pela criança surda para comunicar-se com os ouvintes estão diretamente ligadas ao tipo de comunicação e de educação vivenciado ao longo da história, que passou por diferentes transições filosóficas: oral clássico, comunicação total, oral auditivo e bilinguismo. Atualmente a discussão sobre a filosofia de educação de surdos recai sobre o bilinguismo, o qual tem como pressuposto teórico o fato de que o surdo deve ser bilíngue: é fundamental adquirir a língua de sinais como primeira língua (L1) e a língua do país como segunda língua (L2), na modalidade oral ou escrita. Logo, oportunizar ao surdo a aqui- 
O que pensam as crianças ouvintes a respeito da inclusão de crianças surdas no ensino regular: um estudo comparativo com crianças brasileiras de uma escola pública e uma

sição da língua de sinais como primeira língua é a forma de oferecer-lhe um meio natural de aquisição linguística, visto que a língua de sinais é de modalidade espaço-visual. O bilinguismo entende o surdo como sujeito participante de uma comunidade linguística minoritária, que possui cultura e língua próprias (FERNANDES, 2003).

O presente estudo tem como foco a descrição de como as crianças ouvintes relatam, por meio da escrita, a inserção de uma criança surda em uma sala de aula de ensino regular. Além disso, busca reconhecer a influência da classe social na aceitação da criança surda.

\section{Método}

\subsection{Sujeitos da amostra}

A pesquisa, realizada no primeiro semestre de 2009 , na cidade de Porto Alegre/RS, contou com 144 crianças de $3^{a}$ a $5^{a}$ série do Ensino Fundamental: 76 crianças ouvintes de uma escola privada e 68 crianças ouvintes de uma escola pública. Aos sujeitos da pesquisa foi apresentado um diário ${ }^{1} \mathrm{com}-$ posto de duas partes. A primeira parte descrevia a chegada de uma aluna nova na turma, a Ana. Os alunos foram informados pela professora de que a aluna era surda. Na segunda parte do diário, as crianças deveriam completar por escrito os acontecimentos dos dois dias seguintes.

As turmas de ambas as escolas foram selecionadas aleatoriamente e realizaram a tarefa num período de aula de 55 minutos. Após a coleta, foi feita análise de conteúdo, ou seja, iniciada a pré-análise, a exploração do material, o tratamento dos resultados e a interpretação (MINAYO, 1996; BARDIN, 1988). Apresentamos, a seguir, o perfil dos sujeitos pesquisados (Tabela 1).

Tabela 1 - Perfil dos sujeitos da pesquisa $(\mathrm{N}=144)$

\begin{tabular}{|c|c|c|}
\hline \multirow{2}{*}{ Variável } & \multicolumn{2}{|c|}{ Tipo de Escola } \\
\hline Série & Pública & Privada \\
\hline $3^{\mathrm{a}}$ & 21 & 27 \\
\hline $4^{\mathrm{a}}$ & 24 & 23 \\
\hline $5^{\mathrm{a}}$ & 23 & 26 \\
\hline & \multicolumn{2}{|c|}{ Média de idade } \\
\hline Série & Pública & Privada \\
\hline $3^{\mathrm{a}}$ & $9 \mathrm{a} 8 \mathrm{~m}$ & $9 \mathrm{a} 11 \mathrm{~m}$ \\
\hline $4^{\mathrm{a}}$ & $12 \mathrm{a} 6 \mathrm{~m}$ & $10 \mathrm{a} 11 \mathrm{~m}$ \\
\hline $5^{\mathrm{a}}$ & $12 \mathrm{a}$ & \\
\hline
\end{tabular}


Houve uma variação entre as idades dos alunos em cada série. Os alunos da escola pública, em todas as séries, têm idade cronológica superior aos alunos da escola privada.

Foi reconhecida uma diferença significativa de nível socioeconômico entre as escolas participantes do estudo. Na maioria das famílias das crianças da escola pública, apenas um dos responsáveis trabalha ou exerce serviços de mão de obra não especializada. Tais fatos refletem uma renda familiar ${ }^{2}$ de meio salário mínimo ( $R \$ 232,5$ ou menos) até dois salários mínimos $(R \$ 930,00)$, o que levou a considerar tais famílias de nível socioeconômico baixo. Já as famílias da escola privada, em que, em sua maioria, ambos os responsáveis trabalham, garantem uma renda familiar maior do que cinco salários mínimos $(R \$ 2.325,00$ ou mais), nível socioeconômico alto.

\section{Resultados e discussão}

A partir da análise do material aplicado e das informações coletadas, foi possível organizar cinco categorias de dados:

$1^{\circ}$. Reconhecimento ou não da diferença (surdez);

$2^{\circ}$. Formas de comunicação encontradas pelas crianças;

$3^{\circ}$. Formas de aproximação extraescolar propostas pelas crianças;

$4^{\circ}$. Sentimentos expressos pelas crianças;

$5^{a}$. Formas de solução da inclusão.

No decorrer da análise qualitativa, os relatos escritos permitiram traçar a dinâmica das relações sociais e os significados que as crianças ouvintes atribuem à inclusão de uma criança surda em sua sala de aula. Iniciamos apresentando a forma como as crianças tentam se aproximar da criança surda, já reconhecendo a diferença que existe entre elas (Tabela 2).

Tabela 2 - Reconhecimento da diferença

\begin{tabular}{|c|c|c|c|c|}
\hline \multirow{2}{*}{ Série } & \multicolumn{2}{|c|}{$\begin{array}{c}\text { Linguagem Oral sem } \\
\text { considerar a surdez } \%\end{array}$} & \multicolumn{2}{|c|}{$\begin{array}{r}\text { Linguagem Oral que considera } \\
\text { a surdez } \%\end{array}$} \\
\cline { 2 - 5 } & Pública & Privada & Pública & Privada \\
\hline $3^{\mathrm{a}}$ & 71,1 & 66,6 & 28,5 & 22,2 \\
\hline $4^{\mathrm{a}}$ & 37,5 & 43,4 & 58,6 & 26,9 \\
\hline $5^{\mathrm{a}}$ & 21,7 & 57,6 & 26 & 15,3 \\
\hline
\end{tabular}


O que pensam as crianças ouvintes a respeito da inclusão de crianças surdas no ensino regular: um estudo comparativo com crianças brasileiras de uma escola pública e uma escola privada

A tabela 2 mostra que as crianças ouvintes pertencentes à escola pública apresentam um percentual alto de uso da linguagem oral sem considerar a surdez, ou seja, falam sem se preocupar com o entendimento por parte da criança surda. São 71.1\% na $3^{a}$ série, e esses resultados vão diminuindo no decorrer das séries, a sugerir que a escolaridade mais avançada traz mais compreensão do que significa a surdez à criança. Resultados semelhantes foram encontrados por Antia (1982): $84 \%$ das crianças ouvintes interagiam com as crianças surdas através da comunicação oral. Por outro lado há crianças que utilizam a linguagem oral levando em consideração a surdez e buscam formas alternativas de comunicação, tais como a escrita, desenhos, LIBRAS e leitura labial. Além da comunicação oral, as crianças expressam outras formas de comunicação a serem utilizadas junto à menina surda (Tabela 3).

Tabela 3 - Formas de comunicação encontradas pelas crianças

\begin{tabular}{|c|c|c|c|c|c|c|c|c|c|c|}
\hline \multirow{2}{*}{ Série } & \multicolumn{2}{|c|}{ Escrita \% } & \multicolumn{2}{c|}{$\begin{array}{c}\text { Desenhos } \\
\%\end{array}$} & \multicolumn{2}{c|}{$\begin{array}{c}\text { Uso de } \\
\text { Libras \% }\end{array}$} & \multicolumn{2}{c|}{$\begin{array}{c}\text { Leitura } \\
\text { Labial \% }\end{array}$} & \multicolumn{2}{|c|}{ Outros \% } \\
\cline { 2 - 11 } & PUB & PRI & PUB & PRI & PUB & PRI & PUB & PRI & PUB & PRI \\
\hline $3^{\mathrm{a}}$ & 4,7 & 7,4 & 0 & 7,4 & 0 & 0 & 14,2 & 4,3 & 23,8 & 11 \\
\hline $4^{\mathrm{a}}$ & 8,3 & 21,7 & 0 & 0 & 2,5 & 21,7 & 0 & 7,6 & 0 & 7,6 \\
\hline $5^{\mathrm{a}}$ & 8,6 & 7,6 & 8,6 & 0 & 56,5 & 34,6 & 15,3 & 15,3 & 0 & 0 \\
\hline
\end{tabular}

À medida que as crianças ficam mais velhas vão conhecendo outras formas de comunicação, como é o caso da Língua de Sinais. Observa-se que, na escola pública, $56,5 \%$ das crianças da $5^{\mathrm{a}}$ série dizem que se valeriam do uso de LIBRAS (mesmo que de forma rudimentar), ao passo que, na escola privada, essa tendência não ocorre. Há uma queda na comunicação da $3^{a}$ para $4^{a}$ série, mas há um aumento do percentual de crianças de $4^{\mathrm{a}}$ para $5^{\mathrm{a}}$ série. Percebe-se que as crianças ouvintes menores não consideram a surdez como um problema de comunicação, ignorando-o.

Talvez tal fato ocorra devido à diferença de idade das crianças das escolas pública e privada. Em todas as séries, as crianças da escola pública são, em média, 18 meses mais velhas, fato que pode ajudá-las a reconhecer a diferença e buscar alternativas de comunicação com a criança surda.

Os dados indicam que há uma variação nas respostas das crianças quanto à forma de comunicação oral, mas uma parte dos sujeitos reconhece que essa comunicação não é suficiente. $\mathrm{Na} 3^{a}$ série, nas duas escolas, há percentuais semelhantes no uso da comunicação que leva em conta a surdez. Já na $4^{a}$ série da escola pública, há um percentual elevado de outras formas de comunicação, ora a escrita, ora LIBRAS, evidenciando uma relação diferente da 
do grupo da escola privada, em que são utilizadas a escrita, LIBRAS e leitura labial. Na $5^{\mathrm{a}}$ série, esse percentual diminui em ambas as escolas. Essa diminuição talvez possa ser explicada pelo fato de que um número significativo de crianças, $21.73 \%$, considera importante o uso de LIBRAS para comunicar-se com a criança surda inserida na turma. Provavelmente por essa razão o grupo usa pouco o recurso de comunicação da escrita e de comunicação não lingüística.

$\mathrm{Na} 3^{\mathrm{a}}$ série, não há crianças que se refiram ao uso de LIBRAS, e a referência começa na $4^{a}$ série, aumentando o percentual na $5^{\mathrm{a}}$ série em ambas as escolas. Vejam-se os exemplos abaixo:

\begin{abstract}
Hoje, quando eu estava olhando TV, vi algo muito interessante: vi dois surdos conversando através de gestos manuais muito rápidos! Resolvi aprender essa técnica. Fiquei tão feliz! Pela primeira vez encontrei uma maneira de me comunicar com Ana!. (5 $5^{\mathrm{a}}$ série -escola privada)

Hoje pela manhã eu e a Ana viemos juntas à escola, agora de tarde, daqui a pouco, eu vou ir para o cursinho de língua de sinais eu vou adorar, afinal eu vou poder

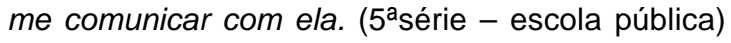

Pelas escritas das crianças, é possível perceber que as crianças ouvintes mais velhas reconhecem a diferença entre surdos e ouvintes, a ponto de se interessarem pela comunicação através de LIBRAS e de comunicação não linguística. Essa diferença não as impede de propor formas de aproximação extra-escolar, as quais apontamos na Tabela 4.

Tabela 4 - Formas de aproximação extraescolar propostas pelas crianças

\begin{tabular}{|c|c|c|c|c|c|c|c|c|c|c|c|c|}
\hline Série & $\begin{array}{c}\text { Não buscar } \\
\text { aproximação } \\
\%\end{array}$ & \multicolumn{2}{|c|}{$\begin{array}{c}\text { Ir na Casa } \\
\%\end{array}$} & \multicolumn{2}{|c|}{$\begin{array}{c}\text { Brincar fora } \\
\text { da aula \% }\end{array}$} & \multicolumn{2}{|c|}{$\begin{array}{c}\text { Ajudar nos } \\
\text { temas \% }\end{array}$} & \multicolumn{2}{|c|}{$\begin{array}{c}\text { Fazer } \\
\text { lanche \% }\end{array}$} & \multicolumn{2}{|c|}{ Outros \% } \\
\hline & PUB & PRI & PUB & PRI & PUB & PRI & $\begin{array}{c}\text { PU- } \\
\text { B }\end{array}$ & PRI & $\begin{array}{c}\text { PU- } \\
\text { B }\end{array}$ & PRI & $\begin{array}{c}\text { PU- } \\
\text { B }\end{array}$ & PRI \\
\hline $3^{\text {a }}$ & 57,1 & 40,7 & 42,8 & 59,2 & 9,5 & 59,2 & 9,5 & 11 & 9,52 & 25,9 & 4,7 & 3,7 \\
\hline $4^{\mathrm{a}}$ & 45,8 & 19,2 & 54,1 & 26,9 & 33,3 & 19,2 & 20,8 & 21,7 & 0 & 4,3 & 20,8 & 4,3 \\
\hline $5^{\mathrm{a}}$ & 56,5 & 34,6 & 39,1 & 38,4 & 21,7 & 34,6 & 8,6 & 0 & 0 & 7,6 & 21,7 & 0 \\
\hline
\end{tabular}

Fora da escola, há uma busca de aproximação maior entre as crianças da escola privada, do que entre crianças da escola pública. É possível que fatores sociais, tais como números de filhos e condições materiais de vida possam estar determinando essa aproximação. Entre estas formas, ir à casa do colega é a alternativa mais frequente registrada pelas crianças nas duas escolas, seguida pelo brincar fora da aula e ajudar nos temas. Vejam-se os exemplos: 
O que pensam as crianças ouvintes a respeito da inclusão de crianças surdas no ensino regular: um estudo comparativo com crianças brasileiras de uma escola pública e uma escola privada

Eu convidei a Ana para vir na minha casa. Nós brincamos muito, no fim da tarde perguntei como ela ficou surda. Ana respondeu meio triste dizendo ela estava entrando num avião e ela foi até a turbina do avião e o avião ligou e ela ficou surda com o barulho da turbina. (4 ${ }^{\mathrm{a}}$ série - escola privada)

E a gente brincou o dia inteiro juntas fizemos grupos lemos juntas e escrevemos e eu aprendi que somos todos iguais não importa se somos surdos, mudos ou cegos. ( $3^{\mathrm{a}}$ série - escola privada)

Parece que as relações sociais entre as crianças surdas e ouvintes, no que tange às atividades extraescolares, poderiam transcorrer sem maiores dificuldades, excluindo-se a efetiva comunicação, o que vem ao encontro da observação de Lacerda (2007, p. 268) de que "a relação entre os alunos é referida como algo que transcorre sem dificuldades aparentes, mas, pelo domínio precário de Língua de Sinais dos alunos ouvintes, se pode deduzir que o aluno surdo não mantém um diálogo mais estruturado ou aprofundado com eles". Nas relações sociais imaginadas pelas crianças se atravessam diferentes sentimentos descritos pelas crianças e apresentados a seguir.

Tabela 5 - Sentimentos expressos pelas crianças

\begin{tabular}{|c|c|c|c|c|c|c|c|c|c|c|c|c|c|c|}
\hline Série & \multicolumn{2}{|c|}{$\begin{array}{c}\text { Aproximação } \\
\%\end{array}$} & \multicolumn{2}{|c|}{$\begin{array}{c}\text { Tristeza } \\
\%\end{array}$} & \multicolumn{2}{|c|}{$\begin{array}{c}\text { Vergonha } \\
\%\end{array}$} & \multicolumn{2}{c|}{$\begin{array}{c}\text { Surpresa } \\
\%\end{array}$} & $\begin{array}{c}\text { Rejeiçãol } \\
\text { Implicância } \\
\%\end{array}$ & \multicolumn{2}{|c|}{$\begin{array}{c}\text { Medo } \\
\%\end{array}$} & \multicolumn{3}{c|}{$\begin{array}{c}\text { Outros } \\
\%\end{array}$} \\
\hline & PUB & PRI & PUB & PRI & PUB & PRI & PUB & PRI & PUB & PRI & PUB & PRI & PUB & PRI \\
\hline $3^{\mathrm{a}}$ & 86 & 100 & 4,7 & 74 & 0 & 0 & 0 & 0 & 0 & 7,4 & 0 & 0 & 38 & 7,4 \\
\hline $4^{\mathrm{a}}$ & 92 & 74 & 0 & 8,6 & 4,1 & 4,3 & 4,1 & 13 & 0 & 13 & 8,3 & 0 & 4,1 & 4,3 \\
\hline $5^{\mathrm{a}}$ & 96 & 100 & 4,3 & 12 & 0 & 3,8 & 4,3 & 0 & 0 & 3,8 & 0 & 0 & 8,6 & 0 \\
\hline
\end{tabular}

A maior parte das crianças, de ambas as escolas, demonstraram interesse em aproximar-se afetivamente da criança surda. O segundo sentimento, que aparece com maior frequência, é a tristeza pela constatação da deficiência ou permanência da limitação. Nesse dado, percebe-se novamente um paradoxo em relação à aceitação da diferença. As crianças demonstram os sentimentos construídos socialmente de pena pela deficiência, pela "falta" que a audição pode estar trazendo àquele sujeito. Veja-se o exemplo abaixo:

Hoje eu não falei com a Ana porque eu não me conformei com a história dela ser surda, mas eu vou tentar amanhã. Será que amanhã eu vou conseguir, não sei não, mas eu vou tentar custe o que custar. Eu estou muito triste porque a Ana é surda. ( $5^{a}$ série - escola pública) 
Nas $4^{\mathrm{a}}$ e $5^{\mathrm{a}}$ séries, aparecem, com pouca frequência, os sentimentos de medo, vergonha e surpresa. Somente na $3^{\mathrm{a}}$ série $38 \%$ das crianças da escola pública descreveram sentimentos diferenciados, tais como preocupação, curiosidade, admiração e proteção, os quais não foram encontrados na escola privada. Cabe ressaltar que, na escola privada, os alunos relatam situações que envolvem provocações e implicância em relação à aluna surda, exigindo, nesses casos, intervenção da professora para auxiliar na solução do conflito.

Possivelmente, a visão sobre surdez ainda é marcada pelo discurso da "falta", do sujeito que não ouve, que não tem um elemento do corpo em funcionamento normal e, por esse motivo, causa admiração, tristeza, estranheza. Esses sentimentos contraditórios foram percebidos nas duas escolas, apesar de aparecerem em discursos diferentes. As crianças, provavelmente, pouco sabem sobre pessoas surdas e ao se depararem com elas reconhecem uma ruptura com a realidade até então conhecida.

Parece que transformar o não familiar em familiar é uma tendência nas representações sociais, pois o estranho suscita diferentes sentimentos, como mostra Moscovici (2003). O medo do estranho pode gerar diferentes sentimentos:

[...] a ameaça de perder os marcos referenciais, de perder contato com o que propicia um sentido de continuidade, de compreensão mútua, é uma ameaça insuportável. E quando a alteridade é jogada sobre nós na forma de algo que 'não é exatamente' como deveria ser, nós instintivamente a rejeitamos porque ela ameaça a ordem estabelecida. (MOSCOVICl, 2003, p. 56)

É possível que as crianças das duas escolas investigadas tenham construído esses sentimentos a partir de informações que provêm do meio, o qual já possui suas crenças e marcas sobre as pessoas surdas. Tais crenças e marcas também perpassam as buscas de solução que algumas crianças descrevem para resolver a inclusão, as quais estão apresentadas na Tabela 6.

Tabela 6 - Formas de solução da inclusão

\begin{tabular}{|c|c|c|c|c|c|c|c|c|c|c|c|c|c|c|}
\hline \multirow[t]{2}{*}{ Série } & \multicolumn{2}{|c|}{$\begin{array}{c}\text { Ficar } \\
\text { amigos } \\
\text { negando a } \\
\text { diferença } \\
\%\end{array}$} & \multicolumn{2}{|c|}{$\begin{array}{c}\text { Buscar } \\
\text { formas de } \\
\text { aprendiza- } \\
\text { gem de um } \\
\text { código } \\
\%\end{array}$} & \multicolumn{2}{|c|}{$\begin{array}{c}\text { Tentar se } \\
\text { solidarizar, } \\
\text { reconhecend- } \\
\text { o a diferença } \\
\%\end{array}$} & \multicolumn{2}{|c|}{$\begin{array}{c}\text { Buscar a } \\
\text { cura para } \\
\text { audição } \\
\%\end{array}$} & \multicolumn{2}{|c|}{$\begin{array}{l}\text { Começar } \\
\text { ouvir } \\
\text { magicamen- } \\
\text { te } \%\end{array}$} & \multicolumn{2}{|c|}{$\begin{array}{c}\text { Ir para outra } \\
\text { escola } \\
\%\end{array}$} & \multicolumn{2}{|c|}{$\begin{array}{c}\text { Outros } \\
\%\end{array}$} \\
\hline & PUB & PRI & PUB & PRI & PUB & PRI & PUB & PRI & PUB & PRI & PUB & PRI & PUB & PRI \\
\hline $3^{a}$ & 76 & 70 & 0 & 7,4 & 24 & 30 & 4,7 & 11 & 4,7 & 0 & 0 & 0 & 4,7 & 7,4 \\
\hline $4^{a}$ & 38 & 35 & 38 & 13 & 58 & 30 & 8,3 & 0 & 0 & 4,3 & 0 & 17 & 4,1 & 22 \\
\hline $5^{a}$ & 30 & 54 & 57 & 31 & 35 & 35 & 4,3 & 0 & 0 & 3,8 & 0 & 3,8 & 0 & 7,7 \\
\hline
\end{tabular}


O que pensam as crianças ouvintes a respeito da inclusão de crianças surdas no ensino regular: um estudo comparativo com crianças brasileiras de uma escola pública e uma escola privada

Há uma riqueza nas diferentes formas que as crianças encontram para concluir a história, que vão desde o ficar amigo dessa pessoa "diferente" até o encaminhamento dessa criança para outra escola.

Em ambas as escolas, na $3^{a}$ série, "ficar amigos negando a diferença" apresenta um percentual maior do que os outros grupos, seguido do "tentar solidarizar-se, reconhecendo a diferença". Os relatos apresentados revelam que muitos alunos reconhecem a diferença, mas se referem à comunicação oral, como se o aluno surdo não apresentasse a deficiência e, magicamente, a criança surda começasse a ouvir e a falar, dado esse também encontrado por Lacerda (2007). Aqui é possível questionar a aceitação da diferença, quando as crianças demonstram preocupação com a cura da surdez, o que revela, ou desvela, que a diferença é vista como uma doença que deveria, se possível, ser curada. Vejam-se as falas de duas crianças:

Quando a Ana chegou, Júlia já estava lá com a sua bicicleta, foram até o hospital e colocaram um microchip no ouvido da Júlia e ela pode ouvir e foram de bicicleta para casa e ficaram grandes amigas. (5 $5^{a}$ série - escola pública)

Ah! Que triste: hoje ela mudou de escola porque não era fácil ler os lábios, mas ela disse que às vezes ela vai visitar esse colégio e no fim acabou tudo bem. (escola privada)

Apesar da surdez e da diferenciada forma de comunicação, os alunos solidarizam-se e reconhecem a diferença, revelando que a criança surda está integrada como se não houvesse problemas de comunicação. A interação entre os alunos é relatada como algo natural, transcorrendo sem dificuldades. $\mathrm{Na}^{\mathrm{a}}$ série, os alunos demonstram interesse em aprender outro código de linguagem, em ambas as escolas.

\section{Conclusões}

O estudo indica que os sujeitos pesquisados estão receptivos à inclusão de uma criança surda e apresentam a intenção de estabelecer com ela uma relação de respeito, amizade e solidariedade, tanto na escola pública como na escola privada. Manifestam interesse em se aproximar da criança surda e em aprender uma nova forma de comunicação, no caso a Língua de Sinais. A maior parte das crianças ouvintes não tem conhecimento da LIBRAS, conforme aparece nas formas de comunicação com a criança surda que descrevem.As crianças da escola pública procuram, com maior frequência, formas de aprendizagem de um código que lhes permita comunicar-se com a criança surda, e uma parte das crianças mais velhas tenta se solidarizar, reconhecendo a diferença. A solução de ir para outra escola foi apontada somente por crianças da escola privada. De modo geral, houve uma descrição de maior receptividade à criança surda nas histórias das crianças da escola pública. 
Possivelmente os sentimentos apresentados pelas crianças ouvintes em relação às crianças surdas ainda estejam marcados pelo discurso das representações sociais construídas em uma visão de sujeitos "coitadinhos", limitados, que possuem uma falta. Salienta-se que a possibilidade de inclusão da criança surda passa pela reconstrução de um currículo que privilegie o trabalho com as diferenças desde a educação infantil, assegurando o uso da LIBRAS por toda comunidade escolar; a aceitação do sujeito surdo como educador tanto de alunos surdos como de alunos ouvintes em disciplinas como Teatro e Artes. Com essas outras formas de linguagem, que não especificamente a linguagem oral, a cultura da surdez pode ser vivida no contexto escolar e revelar que não há culturas melhores ou piores, mas, sim, culturas diferentes (FERNANDES, 2003).

É importante destacar que a inclusão da criança surda no ensino regular não é apenas uma questão de aprendizagem de uma língua diferente pelos ouvintes. Deve-se ter em mente que a função da linguagem, e da língua, não é somente de comunicação, mas também, ou principalmente, de desenvolvimento dos processos cognitivos superiores, salientando-se o direito que a criança surda tem de adquirir e desenvolver linguagem nos diferentes contextos educativos.

O estudo indicou que os alunos ouvintes têm a intenção de efetuar alguma forma de comunicação com os alunos surdos e que poderiam realizar momentos de integração também fora do ambiente de sala de aula em ambas as classes sociais pesquisadas. Como conclusão, percebe-se que há necessidade de um trabalho de preparação das crianças do ensino regular que vão receber um colega com necessidades especiais. É fundamental levar em conta os sentimentos dos alunos ouvintes em busca de formas de aproximação e comunicação. São formas que levam em consideração a possibilidade de ver o outro a partir de sua diferença, sem a necessidade de categorizações e de inscrever o surdo dentro de fronteiras preestabelecidas.

\section{Referências}

ANTIA, S. D.; KREIMEYER, K, H. Peer interaction of deaf and hard-of-hearing children. In: MARSCHARK; SPENCER (Org.). Deaf studies, language and education. New York, 2003.

BARDIN, L. Análise de conteúdo. Lisboa: Edições 70,1988.

BEDIN, V. Diversidade e intersubjetividade em laboratórios de aprendizagem do I Ciclo da Rede Municipal de Ensino de Porto Alegre - RS. 2007, p. 130. Dissertação (Mestrado em Educação), Faculdade de Educação, Universidade do Rio Grande do Sul, Porto Alegre, 2007.

BEYER, H. O. Inclusão e avaliação na escola de alunos com necessidades educacionais especiais. Porto Alegre: Mediação, 2005. 
O que pensam as crianças ouvintes a respeito da inclusão de crianças surdas no ensino regular: um estudo comparativo com crianças brasileiras de uma escola pública e uma escola privada

BITTENCOURT, Z. Z. L. C; MONTAGNOLI, A. P. Representações sociais da surdez. Medicina, Ribeirão Preto, v. 40, n. 2, p. 243-249, 2007.

DECLARAÇÃO de Salamanca. Disponível em: <http://unesdoc.unesco.org/ images/0013/001393/139394por.pdf>. Acesso em: 28 jun. 2009.

FERNANDES, E. Linguagem e surdez. Porto Alegre: Artmed, 2003.

LACERDA, C. B. F. O que dizem/sentem alunos participantes de uma experiência de inclusão escolar com aluno surdo. Revista Brás. Ed. Espe, Marília, v. 13, n. 2, p. 257-280, maio/ago. 2007.

MACIEL, R. Educação inclusiva: um estudo a partir de uma proposta inclusiva alemã. 2007, p. 139. Dissertação (Mestrado em Educação), Faculdade de Educação, Universidade do Rio Grande do Sul, Porto Alegre, 2007.

MINAYO, M. C. S. O desafio do conhecimento: pesquisa qualitativa em saúde. São Paulo: Hucitec-Abrasco, 1996.

MOSCOVICI, S. Representações sociais: investigações em psicologia social. Petrópolis: Vozes, 2003.

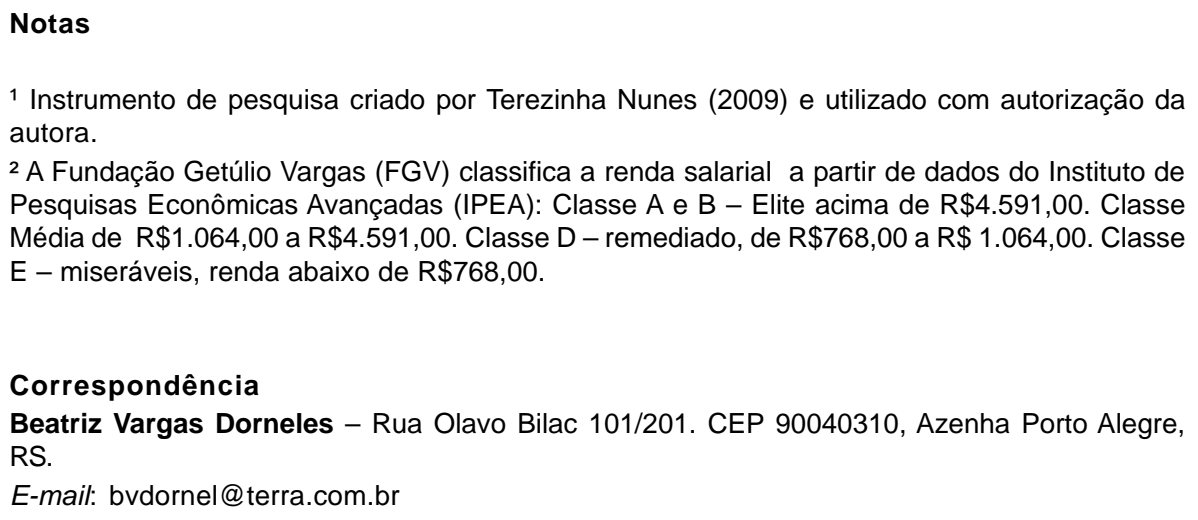
autora.

${ }^{2}$ A Fundação Getúlio Vargas (FGV) classifica a renda salarial a partir de dados do Instituto de Pesquisas Econômicas Avançadas (IPEA): Classe A e B - Elite acima de $R \$ 4.591,00$. Classe Média de $R \$ 1.064,00$ a $R \$ 4.591,00$. Classe $D$ - remediado, de $R \$ 768,00$ a $R \$ 1.064,00$. Classe $\mathrm{E}$ - miseráveis, renda abaixo de $\mathrm{R} \$ 768,00$.

\section{Correspondência}

Beatriz Vargas Dorneles - Rua Olavo Bilac 101/201. CEP 90040310, Azenha Porto Alegre, RS.

E-mail: bvdornel@terra.com.br

Recebido em 20 de maio de 2010

Aprovado em 27 de junho de 2010 